\title{
Hybrid nanoliposome as a targeted growth inhibitor for Cervical Carcinoma Cell line
}

\author{
Noor A. Awad* \\ Nahi Y. Yassen \\ Amer T. Tawfeeq \\ Kismat M. Turki*
}

\author{
MBCHB, MSc \\ ** PhD \\ $*$ PhD \\ PhD
}

\section{J Fac Med Baghdad 2015; Vol.57, No.4 Received Sept. 2015 Accepted Oct . 2015}

Background: targeted cancer nanotherapy represents a golden goal for nanobiotechnology to overcome the severe side effects of conventional chemotherapy. Hybrid nanoliposomes (HLs) composed of L- $\alpha$ dimyristoylphosphatidylcholine (DMPC) and Polyoxyethylene (23) dodecyl ether (C12 (EO)23 ) can integrate selectively into the cancer cell membrane inducing cancer cell death.

Objectives: to assess the capacity of locally (in hose) synthesized hybrid nanoliposome to inhibit the growth of cervix cancer cells (HeLa) and induce apoptosis.

Patients and Methods: hybrid nanoliposomes(nHLs) synthesized by sonication method from a mixture of $90 \%$ mol DMPC and 10\% mol C12(EO)23 in tissue culture media RPMI-1640 for 6 hours at 300W and $40^{\circ} \mathrm{C}$ then filtration with $0.2 \mu \mathrm{m}$ filter. Shape and size characterized with scanning electron microscope (SEM). Viability of HeLa cell and normal lymphocytes challenged with HLs were determined using MTT assay. Induction of apoptosis in the challenged cells was examined by staining with fluorescence dye mix acridine orange/propidium iodide.

Results: synthesized nHLs were in nanozise range and selectively inhibited HeLa cells proliferation with IC50 of $0.2 \mathrm{mM}$ DMPC with no effect against normal lymphocytes. Apoptosis was evident in $88.24 \%$ of HeLa cells population treated with HLs.

Conclusion: synthesized nHLs may considered as promising nanotherapy, this study recommends further inspections for the mechanism of action of nHLs and their capabilities to inhibit other types of cancers both in vitro and in vivo.

Key words: hybrid nanoliposomes, liposomes, HeLa cells, apoptosis, nanotbioechnology.

\section{Introduction :}

Beside breast cancer, cervical carcinoma represents one of the fatal cancers that could affect women at child berth life time. In Iraq, unfortunately there is no resent statistics published that clarify the level of diagnosed women or deaths statistics related to this type of cancer. The last report published by the Iraqi cancer registry center which runs by the Ministry of health dated back to 2011, and this type of cancer was not in the first ten cancers registered in Iraq at that time [1]. However, according to the U.S center for disease control and prevention (CDC) web site, in 2012, an estimated of 12,042 women in the United States was diagnosed with cervical cancer, and an estimated of 4,074 die of the disease [2-4]. This type of cancer cannot be cured unless it has been diagnosed in its early stages, a situation not happing systematically especially in the third world countries. Therefore, women diagnosed with this cancer would go through all the conventional therapies available such as surgery, chemotherapy and radio therapy with all the side effects consequences related to these therapies (5).

*Clinical biochemistry - Collage of Medicine-Baghdad University. **Cancer Cytogenetics - Iraqi Center for Cancer and medical Genetics Research-Al-Mustansiriyha University.
This emphasizes the need for cures with less invasive consequences to treat this type of cancer.

Nanobiotechnology represent know an advanced science in cancer research, not only to develop new nano-diagnosis tools to achieve higher specificity, but also to invent new therapies with more specific cancer cell targeting and less side effects (6). Hybrid liposomes (HLs) are one of promising new therapies going under research emphasis more than a decade now; they were first developed by Ueoka et. al, in Japan (7). They differ from conventional liposomes in that they do not encapsulate any therapeutic chemical compound, so they do not categorized in the field of drug delivery systems. Hybrid liposome intended to be a therapeutically by themselves (8). Nano-hybrid liposomes are concentrated with the same procedure but their size should be under $100 \mathrm{~nm}$ to gain the character of nanoparticle (9).

\section{Patients and Methods:}

L- $\alpha$-dimyristoylphos phatidylcholine (DMPC) (NOF, Japan), Polyoxyethylene (23) dodecyl ether (C12(EO)23) (Sigma Alderich, USA), 3- (4, 5-dimethylthiazol-2-yl) 2, 5-diphenyltetrazolium bromide (MTT) (Sigma Alderich, USA), RPMI- 
1640 tissue culture media with HEPES and L-glutamate (USBiological, USA), fetal calf serum (Capricorn, Germany) , Acridine orange and Propidium Iodide (Sigma Alderich, USA), Ficoll solution (Capricorn, Germany), Streptomycin and Gramycine (Ajantaa pharm, India). Syringe filters $0.22 \mu \mathrm{m}$ (ThermoFisher, USA), Cervical cell carcinoma cell line (HeLa) supplied from Iraqi Center for Cancer and Medical Genetics Research (ICCMGR). Cells were grown in tissue culture vessels and 96 well plates (Santa Cruz, USA). The preparation of hybrid nanoliposomes (nHLs) carried out according to the method described by Komizu et al., 2011(10). That was at the molecular biology department of the ICCMGR, different concentrations of $90 \%$ mol DMPC mixed with $10 \%$ mol C12(EO) ${ }_{23}$, dissolved in $1 \mathrm{ml}$ DMSO added to $9 \mathrm{ml}$ of serum free RPMI (1640) media and sonicated at $45{ }^{\circ} \mathrm{C}$ with $300 \mathrm{~W}$, for $6 \mathrm{hrs}$, followed by filtration with 0.20 $\mu \mathrm{m}$ filter. Shape and size distribution of the prepared nHLs determined by scanning electron microscope (VEGA3 TESCAN, Czech republic) Normal lymphocytes were isolated for normal individual (volunteered willingly for the purpose of this experiment) according to method of Zhang et.al,(2005) (11). Cell viability assay using MTT carried out according to the method of Al-Hilli at.el,(2011) at 570nm, HeLa cells and normal lymphocytes challenged with different concentrations of nHLs ranged from $0.1 \mathrm{mM}$ to $0.4 \mathrm{mM}$ (on basis of DMPC mol.wet.) (12). Cell apoptosis determined according to the method of Martin and Lenardo (2001) staining with acridine orang and propidium iodide fluorescence dyes mixture $(\mathrm{AO} /$ PI) (13), cells imaged with CCD camera (Micros, Austria) under fluorescence microscope (Micros, Austria). Apoptotic, necrotic, and normal cells were counted using Microvisible Image analyzing software (Micros, Austria). Statistical analysis to define significant differences among the means of control untreated and treated cells were carried out using ANOVA and post hoc t-test.

\section{Results:}

Figure (1) represents SEM Image for the synthesized nHLs indicating nano-sized particles and particle size distribution. Nanoparticles from 20 to 100 nanometer sizes represent $56 \%$ of the population the rest sizes represent $44 \%$.

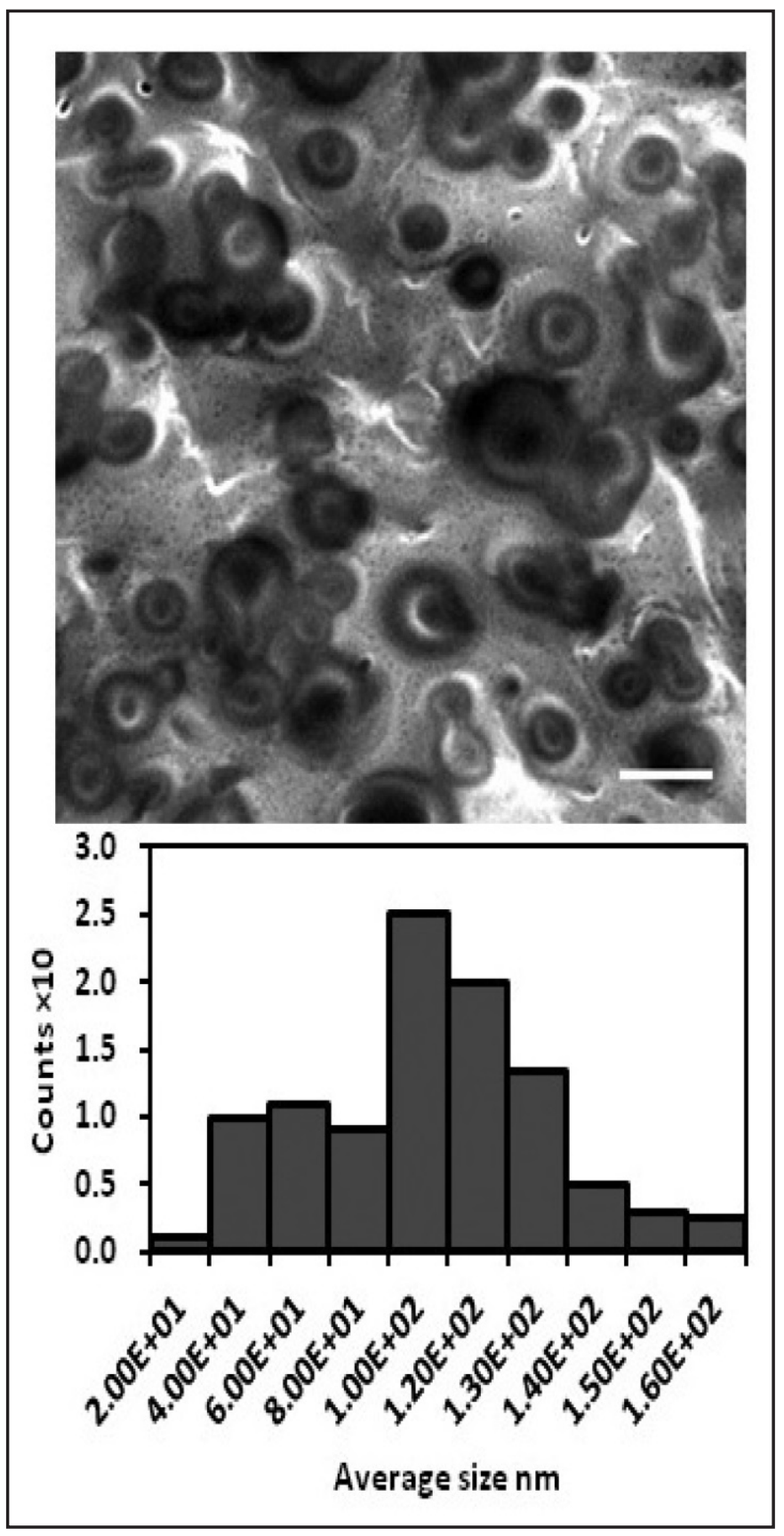

Figure (1): synthesized nHLs by the described procedure, upper: SEM image white arrow indicate $100 \mathrm{~nm}$ liposome particle, lower: particle size distribution, white bare scale $=200 \mathrm{~nm}$.

The growth inhibition of HeLa cells and normal lymphocytes are shown in figure (2) appearing the anticancer growth inhibition selectivity of the synthesized nHLs. The IC50 for HeLa cells was $0.2 \mathrm{mM}$ of hybrid nanoliposomes, this concentration reduce HeLa cells growth by $52.56 \pm 0.0304$ $( \pm$ S.E.); this concentration did not effect normal humane lymphocytes by any means. 


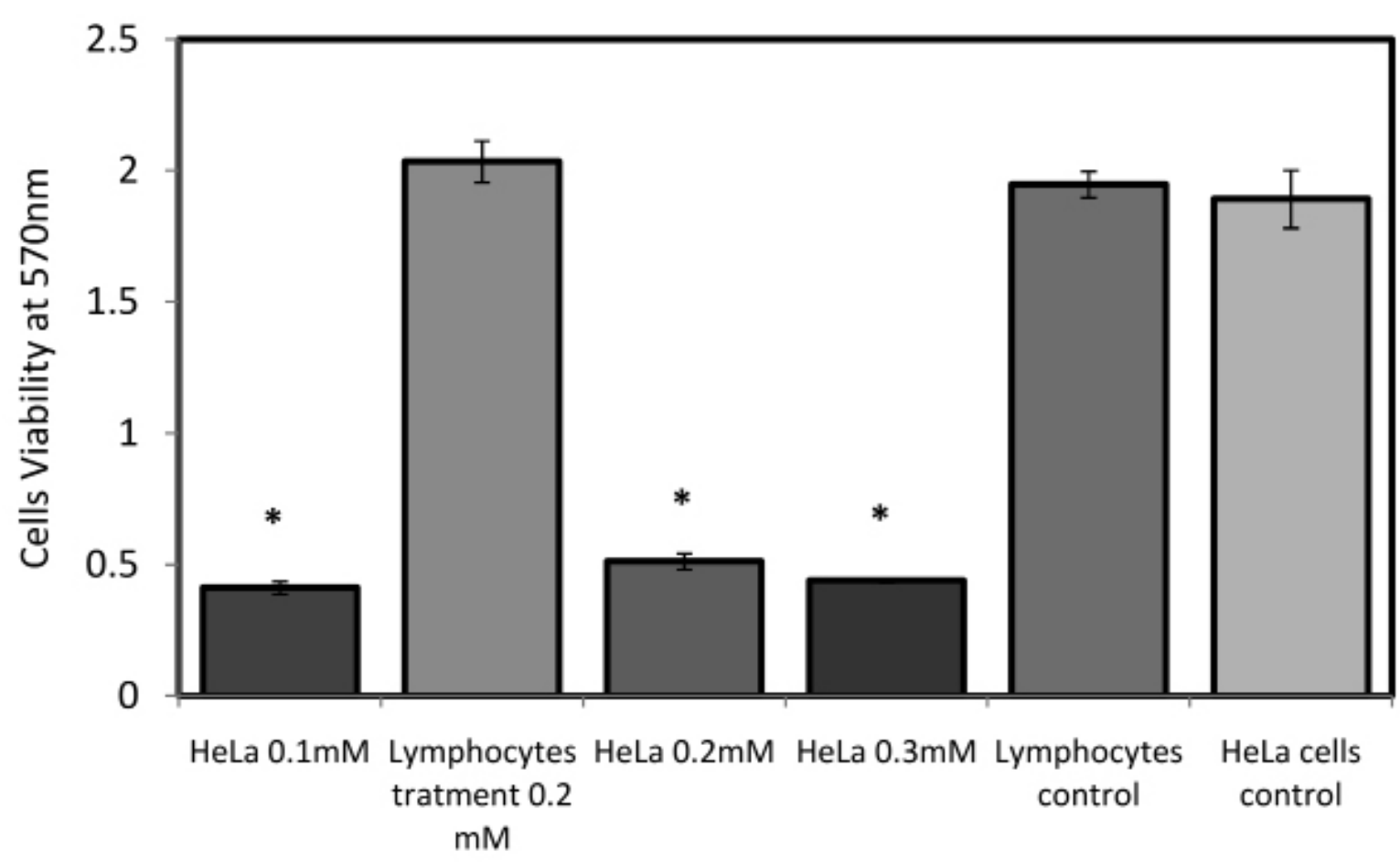

Figure 2: Cell viability levels of HeLa cells and normal humane lymphocytes incubated with hybrid nanoliposomes (nHLs) compared to control untreated cells for $24 \mathrm{hr}$ at $37^{\circ} \mathrm{C}$, * represent significant differences between the mean \pm S.E. of $\mathrm{nHLs}$ treated and control $(\mathbf{p}<\mathbf{0 . 0 0 1})$.

The HeLa cell population incubated with the IC50 concentration of nHLs $(0.2 \mathrm{mM})$ suffered from apoptosis according to the results of AO/PI mix staining figures (3 and 4). The apoptotic cells in treated HeLa cells consist $88.24 \%$ of population, whereas it did not exceed $1.55 \%$ of the population in untreated control cells.

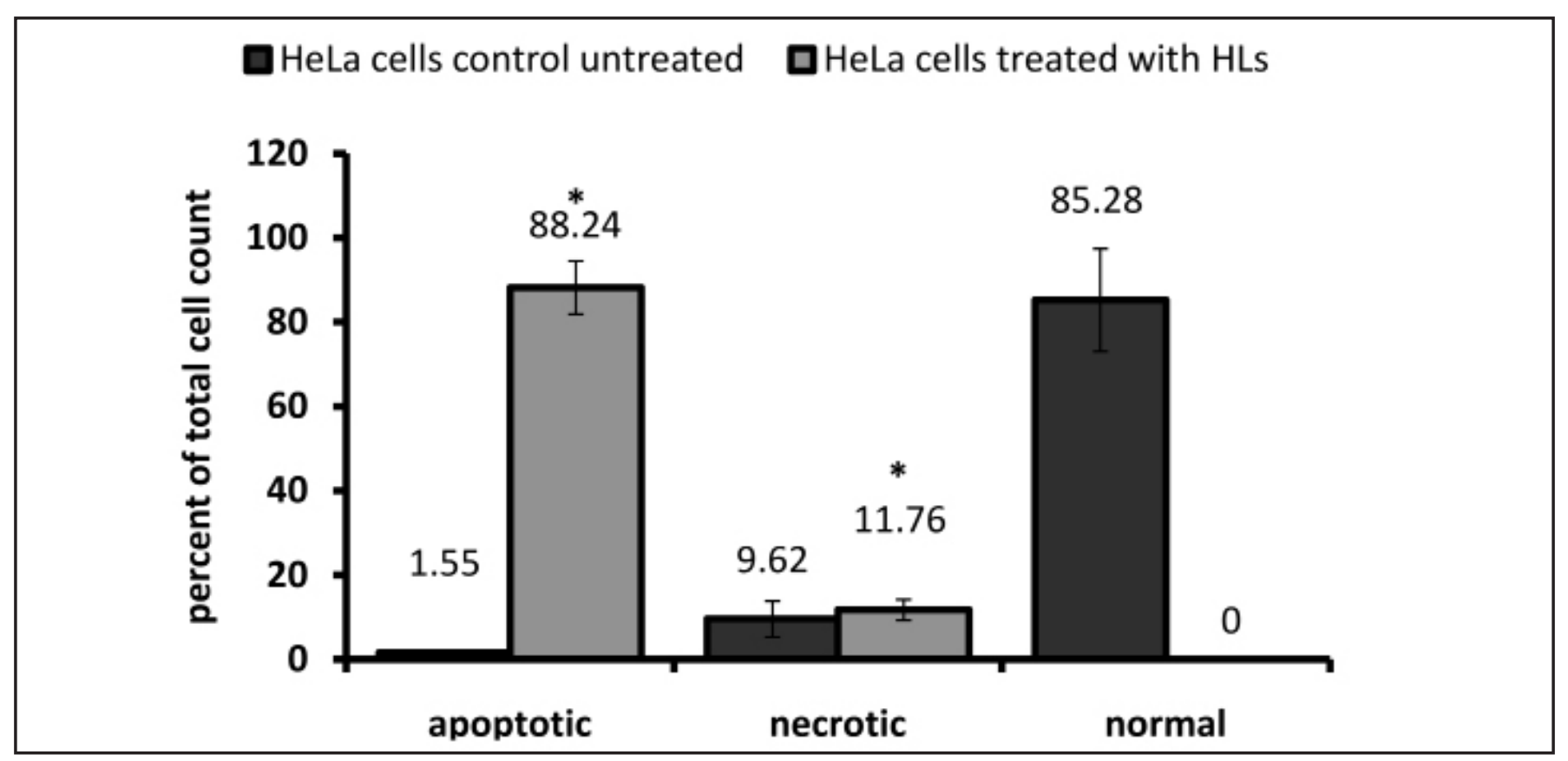

Figure 3: Percent of HeLa normal, apoptotic, and necrotic cells appeared in control untreated cells and cells incubated with HLs for $24 \mathrm{hr}$ at $37^{\circ} \mathrm{C}$, columns represent the means percentages, whiskers on columns represent \pm S.E. * significant difference between the means of control and treatment $(\mathbf{p}<0.01)$. 

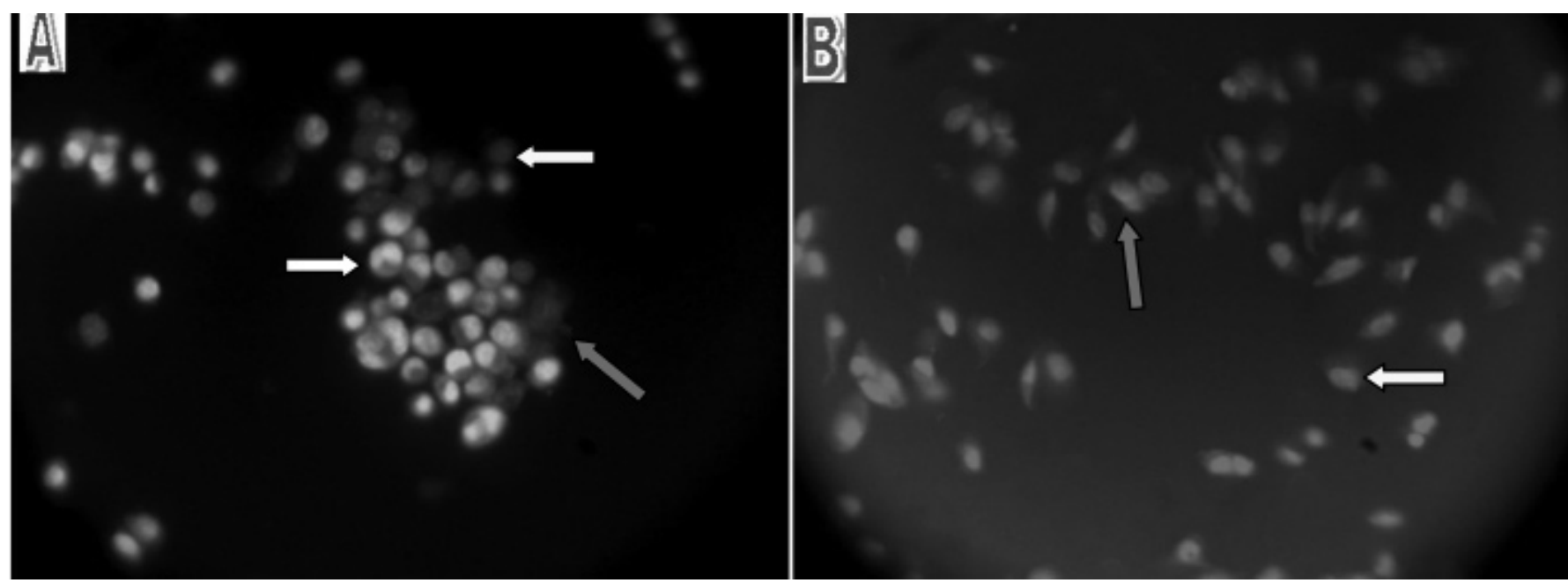

Figure 4: Representative image under fluorescence microscope for control untreated HeLa cells (A), and HeLa cells incubated with $\mathrm{HLs}$ for $24 \mathrm{hr}$ at $37^{\circ} \mathrm{C}(\mathrm{B})$, white arrow point toward normal cell, yellow arrow point toward necrotic cells, red arrow point toward apoptotic cells.

\section{Discussion:}

Dynamics of plasma membranes are biological characteristic of cancer cells. Cancer cell membranes continuously appear to changing in lipid composition and construction, this give cancer cell membranes fluidity in grater manner than cell membrane of normal cells. Leukemia and lymphoma cells membranes have more unsaturated lipid and less cholesterol this makes them with higher fluidity compared to normal lymphocytes (14-18). The same thing was observed for other cancer cell membranes (19-20). This fluidic dynamics of cancer cells membrane seems to be fundamental character and it enhances features of unlimited proliferation ability, invasive potential, and metastatic capacity (21-22). In this study, the ability of hybrid liposome to impose lethal effect on cancer cells was examined. The rationale behind that was the hypothesis of matching between the fluidity of cancer cell membrane and the fluidity of hybrid liposomes. This matching allows the hybrid liposome to integrate into the cancer cell membrane leading to changing cell membrane fluidity toward more rigidity and less flexibility which induce cancer cell death (23). The detection of the capability of nHLs to induce cancer cell death was examined with MTT procedure. This assay recognize the dead cell from live cell by the ability of living cell to convert the yellow color of MTT to blue color of formazan crystal. The more viable cells are there the more blue color will be formed. The blue color intensity can be determined by light absorbance at $570 \mathrm{~nm}$. The result of this experiment indicated that the synthesized hybrid nanoliposome was able to induce HeLa cells death spearing the live of normal humane lymphocytes. In order to provide an evident that the selective HeLa cells growth inhibition was due to occurrence of apoptosis event, a commune procedure of staining with fluorescence dyes was conducted. Staining cells under certain effect with fluoresces dye mixture especially acridine orange and ethidium bromide or propidium iodide is well documented procedure. This procedure used to estimate either through direct visual counting or special software the level of cells that go under apoptosis or necrosis or even stile in normal condition. After staining the cells under effect with the mixture of these dyes, three types of colored cells could be seen under fluoresces microscope. Live cells will appear in green color with uncondensed or not fragmented nuclei, while the cells which entered the early stage of apoptosis will appear in green color with either condensed or fragmented nuclei. The cells under necrosis event will stained red and have uncondensed or not fragmented nuclei, whereas cells in late stage apoptosis will appear in red color and have condensed or fragmented nuclei. Results for HeLa cells of this assay are presented in figure (3) and figure (4). Normal cells in control untreated replicates composed $85 \%$ of the population, but this population dropped to zero in cells incubated with HLs for $24 \mathrm{hr}$. the counts for apoptotic characteristic cells in control untreated cells were $1.55 \%$ of the population in the examined replicates, this percentage increased up to $88.24 \%$ of the population in the examined replicates. The necrotic cells in both untreated and treated cells represented only one tenth of the population examined composing $9.62 \%$ and $11.76 \%$. All the cells examined in the HLs treated cells were having the late apoptosis characteristics, they stained red and have condensed or fragmented nuclei. From this note, the $24 \mathrm{hr}$ incubation period was fairly enough to bring more than $88 \%$ of the cell population to the late stage of apoptosis. These results indicate clearly that HLs induce apoptosis in HeLa cells.

\section{Conclusions:}

In house synthesized hybrid nanoliposome was able to selectively inhibit the growth of cervical cell carcinoma 
(HeLa cell line) and this inhibition was due to the induction of apoptosis. These results should be examined more carefully and determination of the exact mechanism of action is a priority.

\section{Authoress Contributions:}

Prof.Dr. Nahi Y.Yassin and Prof.Dr. Kismatt supervised the research .

Dr. Amer T.Tawfeq and Dr. Noora A.Awad designed, performed the experiments, and write the manuscript.

\section{References:}

1- Republic of Iraq, ministry of health, Iraqi cancer registry report. Iraqi cancer board, Iraqi cancer registry center. 2011.

2- National Institutes of Health. Cervical Cancer. NIH Consensus Statement. 1996. 14, 1-38.

3- United States Cancer Statistics Working Group. United States Cancer Statistics: 1999-2012 Incidence and Mortality Web-based Report. Atlanta (GA): Department of Health and Human Services, Centers for Disease Control and Prevention, and National Cancer Institute; 2015.

4- Centers for Disease Control and Prevention, Department of Health and Human Services, cervical cancer statistics. 2015.

5- Cervical Cancer report, American cancer society. 2015.

6- Mansoori, G. A.; Mohazzabi, P.; McCormack, P. and Jabbari, S. Nanotechnology in cancer prevention, detection and treatment: bright future lies ahead. World Rev. Sci. Tech. Sustainable Dev. 2007. 4, Nos. 2/3.

7- Ueoka R, Matsumoto Y, Moss RA, Swarup S, Sugii A, HaradaJ, Kikuchi Y and Murakami Y. Membrane matrix for the hydrolysis of amino acid esters with marked enantioselectivity. J. Am. Chem. Soc. 1988. 110, 1588-1595.

8- Hchihara H, Nagami H, Kiyokawa T, Matsumoto Y, and Ueoka, R. chemotherapy using hybrid liposomes along with induction of apoptosis. Anticancer Res. 2008. 28, 1187-1196.

9- Robert T, Sylvain C, Todd O, Patrick P, Andrey G, Wei L, Gary R, Ravi P, Himanshu T. Small particles, big impacts: A review of the diverse applications of nanofluids. J. Appl. Phys.2013. 113, 011301.

10-Komizu Y, Nakata S, Goto K, Matsumoto Y, and Ueoka R. Membrane-Targeted Nanotherapy with Hybrid Liposomes for Tumor Cells Leading to Apoptosis. ACS Med. Chem. Lett. 2011, 2, 275-279.

11-Zhang J, Dong Z, Zhou R, Luo D, Wei H, and Tian Z. Isolation of Lymphocytes and Their Innate Immune Characterizations from Liver, Intestine, Lung and Uterus. Cellular \& Mole. Immun.2005. 2, 271-280.

12-Al-Hilli Z. A. A, Tawfeeq A. T, Al-Majedy Y. K, Kadhim H. M, Al-amiry A. A. H, Jafar T. H, Kalil S. K, Ghedan A. F, Hussein R. A. Novel Synthetic 3-Amino-2-Methylquinazolin4(3H)- one (L) Induce Apoptosis and Modulate Antioxidant Enzyme Activity in Some Cancer Cell Lines. Iraqi J. Cancer.
Med. Gen. Res.2011. 4, 5-16.

13-Martin D and Lenardo M.). Morphological, biochemical, and flow cytometric assays of apoptosis. Cur. Proto. Mol. Biol. Chapter 14: Unit 14.13. 2001

14-Inbar M, Shinitzky M, Sachs L. Microviscosity in the Surface Membrane Lipid Layer of Intact Normal Lymphocytes and Leukemic Cells. FEBS Lett. 1974. 38, 268-270.

15-Inbar M, Goldman R, Inbar L, Bursuker I, Goldman B, Akstein E, Segal P, Ipp E, Ben-Bassat I.. Fluidity Difference of Membrane Lipids in Human Normal and Leukemic Lymphocytes as Controlled by Serum Components. Cancer Res. 1977. 37, 3037-3041.

16-Petitou M., Tuy F, Rosenfeld C, Mishal Z, Paintrand M, Jasnin C, Mathe G, Inbar M. Decreased Microviscosity of Membrane Lipids in Leukemic Cells: Two Possible Mechanisms. Proc. Natl. Acad.Sci. U.S.A. 1978. 75, 2306-2310.

17-Van Blitterswijk W. J, De Veer G, Krol J. H, Emmelot P. Comparative Lipid Analysis of Purified Plasma Membranes and Shed Extracellular Membrane Vesicles from Normal Murine Thymocytes and Leukemic GRSL Cells. Biochim. Biophys. Acta, 1982. 688, 495-504.

18-Shinitzky, M.. Membrane Fluidity in Malignancy. Adversative and Recuperative. Biochim. Biophys. Acta.1984.738, 251-261.

19-Sok M, Sentjurc M, Schara M. Membrane Fluidity Characteristics of Human Lung Cancer. Cancer Lett. 1999. 139, 215-220.

20- Yukihara M, Komizu Y, Tanoue O, Matsushita T, Matsumoto Y, Ueoka R. (2010). Specific Accumulation and Antitumor Effects of Hybrid Liposomes on the Growth of Lung Tumor Cells. Yakugaku Zasshi, 2010. 130, 1581-1587.

21-Zeisig R, Kokli T, Wiesner B, Fichtner I, Sentjur M.. Increase in Fluidity in the Membrane of MT3 Breast Cancer Cells Correlates with Enhanced Cell Adhesion in Vitro and Increased Lung Metastasis in NOD/SCID Mice. Arch. Biochem. Biophys. 2007. 459, 98-106.

22-Gonda K, Watanabe T. M, Ohuchi N, Higuchi H). In Vivo Nano-Imaging of Membrane Dynamics in Metastatic Tumor Cells Using Quantum Dots. J. Biol. Chem. . 2010, 285, 27502757.

23- Komizu Yi, Ueoka T, Yukihara M, Ichihara H, Matsumoto $Y$, and Ueoka R. Hybrid Nanoparticles Inhibit Growth of Human Prostate Cancer Cells by Induction of Apoptosis. SOJ Pharm Pharm Sci. 2014. 1, 1-4. 